NASA Technical Memorandum 79141

(MASA-TH-79141) PRIGARY BLBCTRIC PROPOLSIOR

FOR FOTORE SPACB GISSIOES (MASA) 45 p BC

A03/AP $\triangle 01$

CSCI 20C

179-22190

Onclas

G3/20 23985

\title{
PRIMARY ELECTRIC PRĆPULSION FOR FUTURE SPACE MISSIONS
}

David C. Byers, Fred F. Terdan, and Ira T. Myers

Lewis Research Center

Cleveland, Ohio

Prepared for the

Conference on Advanced Tecinnology for Future Space Systems

sponsored by the American Institute of Aeronautics and Astronautics

Langley, Virginia, May 8-11, 1979

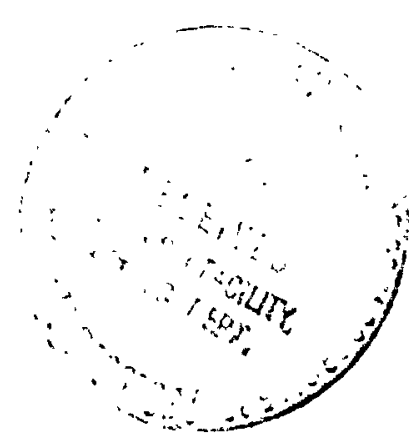




\title{
PRIMARY ELECTRIC PROPULSION FOR FUTURE SPACE MISSIONS
}

\author{
by David C. Byers, Fred F. Terdan, and Ira T. Myers \\ National Aeronautics and Space Administration \\ Lewis Research Center \\ Cleveland, Ohio

\section{INTRODUCTION}

Primary propulsion systems for space operations have significant impact on mission approaches, capabilities, and costs. Driver issues such as number of Earth launches, structural requirements, reuse/refurbishment strategies, and deployment options, depend to first order on the characteristics of the space propulsion system. Electric propulsion may significantly enhance or enable planetary and geocentric space missions, (1-3) For Low Earth Orbit (LEO) to Geosynchronous Earth Orbit (GEO) transfer, the propellant mass required with the best chemical propulsion concepts is several times that of the payload. With electric propulsion, however, the orbit transfer propellant is a small fraction of payload mass. This can result in a dramatic reduction in the mass required in LEO for many geocentric missions. Consequently, the volume of electric propulsion systems for energetic missions is usually significantly less than that of chemical systems. For large low density payloads this factor also can stroi. , reduce launch requirements. The low acceleration characteristic of electric propulsion is consistent with the low force loading approaches required for fragile, Large Space Systems (LSS). As a final example, electric propulsion has a demonstrated long term compatibility with the geocentric space environment. (4) This feature may in part enable return/refurbishments strategies with geocentric payloads if they appeared desirable.

Studies have been performed to define optimal primary electric propulsion concepts for many space missions. These studies evaluated small(5) to very large( 3 ) geocentric missions and various planetary missions. (6-8) The diversity in the requirements resulted in optimal electric propulsion systems with very different characteristics. The thrust systems sele:ted ranged from those employing a baseline $30-\mathrm{cm}$ system $(5)$ to ones using advanced thruster and PMAC concepts. (3) The long range nature of many of the missions studied caused considerable uncertainty $(3)$ with regard to the appropriate choice of thrust system characteristics.

It is the intent of this paper to provide data and a methodology to allow preliminary definition of electric propulsion systems. To allow application to a range of missions, the elements comprising the thrust system are described in parametric fashion. As an example, thruster performance is presented as a function of specific impulse and prupellant type. Two PMAC approaches are presented to illustrate use of the methodology. Nc attempt was made to include power source characteristics 
in the system description. This subject has been comprehensively discussed elsewhere. (9) One PMAC concept assumed a DC power input to the thrust system and all thruster power conditioned in a conventional manner. (6) The other PMAC approach assumed an $\mathrm{AC}$ power source.

To provide insights into the methodology, two point system designs are formulated from the parametrically presented element data. As it is recognized that element technology will change with time, the methodology selected allows an easy incorporation of such changes. It is hoped that the information provided will allow convenient preliminary descriptions of electric thrust systems for a broad set of missions.

\section{SYSTEM APPROACH}

The overall system consists of a thrust module and an interface module as shown in Fig. 1. For purposes of calculation the power transmission line is also included as part of the system. This approach has been used before $(6,10,11)$ and is convenient for parametric evaluation of a thrust system.

Elements which may be contained in each modulue are shown in Fig. 1. The elements shown in unshaded boxes are considered common to all thrust systems. The characteristics of these elements will vary with system level assumptions such as propellant type and specific impulse. The characteristics of the elements shown in shaded boxes depend on the system approach selected.

In the following sections the characteristics of the various system elements will first be presented. This will be followed by the description of the general methodology which predicts overall system characteristics.

\section{ELEMENT DESCRIPTION}

\section{Thruster}

Performance. - The performance of an electron-bombardment ion thruster is specified if the input power, $\mathrm{P}_{\mathrm{T}}$, and thrust, $\mathrm{T}$, are predicted as a function of specific impulse, $I_{S P}$ (All symbols used herein are defined in Appendix A). Such a performance description must account for the propellant type, thruster size, propellant utilization efficiency, and thrust and power losses due to several factors. A parametric analysis of thruster performance was performed and the details are given in Appendix B. For clarity, the results of Appendix B will be summarized below.

The performance envelope of a thruster may be predicted if the limits on performance are known. The fundamental limits upon thruster performance are the maximum ion current density that may be extracted from the ion accelerator grids 
(the perveance limit) and the allowable range of the ratio of net to total accelerating voltages (R) over which a thruster may be operated.

The maximum ion current density is specified by the propellant ion type (more precisely the charge to mass ratio) and the total accelerating voltage. 'The total accelerating voltage, $\Delta \mathrm{V}$, is the sum of the positive grid voltage and the absolute value of the voltage applied to the negative grid. The upper limit of $\Delta \mathrm{V}$ is specified by the value above which high voltage breakdown occurs between the accelerator grids. For closely spaced state-of-art accelerator grids, values of $\Delta \mathrm{V}$ greater than 2000 volts have been demonstrated. Accelerator grids were assumed to be clostly spaced to maximize the ion current density that may be obtained. (12) If operation at very high specific impulse is required, it is necessary to increase the grid-to-grid spacing resulting in lower ion current densities than assumed. While uncertain, 3000 volts is probably near the upper limit of $\Delta \mathrm{V}$ possible with closely spaced grids made with present materials and fabricating procedures.

The specific impulse, at an assumed $\Delta V$ and with a specific propellant ion, may be selected by operating at a given value of $R$. With two grid ion accelerators the allowable range of $R$ was found to be between about 0.7 and 0.9 . At the lower value, ions begin to directly intercept the negative grid and the higher value is about the point where ion beam electrons begin to backstream into the thruster. Data have been recently been taken $(13,14)$ which indicate that values of $R$ between about 0.2 and 0.9 are allowable with three grid accelerator systems. This range of $R$ will be assumed allowable in this paper.

The allowable ranges of $\Delta V$ and $R$ do, then, specify the operating limits of electron-bombardment thrusters (Appendix B). Figures 2 and 3 show thrust and power density parameters as functions of a specific impulse parameter. The use of Figs. 2 and 3 to obtain the input power and output thrust of a thruster is described in detail in Appendix B. For a fixed assumed total accelerating voltage, the attainable range of the specific impulse parameter is specified by the limits on $R$. The specific impulse may be obtained from the specific impulse parameter when the propellant ion mass, the propellant utilization efficiency, and the thrust loss factor are specified. Table I shows these parameters which have been obtained with four different propellants and are felt to be reasonable estimates of performance over an extensive range of thruster size. It is likely that the performance parameters shown on Table I will improve as new technologies, such as improved plasma magnetic containment approaches, $(15,16)$ are developed.

Figures 2 and 3 show that the thrust and power densities are very sensitive to total accelerating voltage. These figures may be used to determine the attainable range of specific impulse for a given propellant and the thrust and power of any size thruster. 
Mass. - The mass of a thruster is dependent both on its size and the technical approaches utilized in its construction. The present baseline, $30-\mathrm{cm}$, mercury thruster is of the two grid, divergent magnetic field type and has a mass of $8.8 \mathrm{~kg}$. In the opinion of the authors, advanced thrusters will be of the three grid type, $(13,14)$ utilize a more complicated magnetic field configuration, $(15,16)$ and operate at higher power densities than the baseline thruster. A preliminary calculation of the impact of these approaches indicated that a circular $30-\mathrm{cm}$ thruster would have a mass of $11.4 \mathrm{~kg}$ when operated at power densities of about a factor of five greater than the baseline thruster. This mass is conservative for inert gas thrusters for which some thruster components, such as propellant isolators, would be much lighter than those of a mercury thruster. Variation of circular thruster mass as a function of thruster size was previously presented (12) Those data were combined with the estimate of 11. $4 \mathrm{~kg}$ for a $\$ 0-\mathrm{cm}$ thruster and the mass of thrusters is presented in Fig. 4. In Fig. 4 the diameter specified is that of the active area of the accelerator grids of a circular thruster. The frontal diameter of a circular thruster is typically about $10-\mathrm{cm}$ greater than the diameter of the active area. Thrusters of noncircular shapes may be desirable in the future and refinement of the data of Fig. 4 would be required if such thrusters were employed.

Dissipated power. - The dissipated powers of system elements is generally important as the thrust system thermal control system must be sized accordingly. The thruster, however, does not require a thermal control system as the dissipated power is radiated to space from the thruster itself. (12)

\section{Gimbal}

The mass of a gimbal for the $30-\mathrm{cm}$ thruster was obtained from the detailed point system design of Ref. 10. A gimbal mass of $3 \mathrm{~kg}$ was assumed for a thruster mass of $8.8 \mathrm{~kg}$. The gimbal design accounted for Shuttle landing loads, Inertial Upper Stage (IUS) loads, and loads from the thruster. It will be assumed that the gimbal mass will remain the same fraction (0.34) of thruster mass as given in Ref 10 and is shown as a function of thruster diameter on Fig. 4. The assumed gimbal mass is expected to be conservative as the structural strength of systems may often be increased faster than the structural mass.

As the gimbals are powered only when active gimbaling occurs the dissipated power will be considered negligible.

\section{Thrust Module Propellant Distribution}

In Ref. 10 the mass of the propellant lines and valves for a 10 thruster mercury system was calculated as $8.4 \mathrm{~kg}$. Exact masses will, of course, depend strongly on the system concept; especially with how the thrusters are distributed. In this study an arbitrary mass of one kilogram per thruster will be charged to the thrust module propellant distribution system. 


\section{Thrust Module Structure}

The thrust module structure serves to cantilever the thrusters and gimbals away from the interface module. This structure is very specific to overall system design and a detailed parametric evaluation is beyond the scope of this paper. The detailed point design of Ref. 10 estimated that a thrust module structure of $36.3 \mathrm{~kg}$ was required to support a total thruster and gimbal mass of $117.3 \mathrm{~kg}$. The structure was sized to account for Shuttle landing loads, IUS loads, and the loads imposed by the thrusters and gimbals. In addition, the thrust module structure accommodated a large total gimbal angle capability of 70 and 30 degrees in two orthogonal directions. As with the gimbals, the mass of the thrust module structure will be assumed to be a constant fraction $(0,31)(10)$ of the thruster plus gimbal mass.

\section{Power Management and Control}

The Power Management and Control (PMAC) system configuration is shown in Fig. 1 with specific elements dependent on the PMAC concept chosen. Two PMAC approaches were selected for analyses in this paper. The first assumed a direct current $(D C)$ power source with conventional $(6,10)$ power processing. The second concept assumed an alternating current $(\mathrm{AC})$ power source which altered some of the PMAC elements used in the conventional approach. In order to provide parametric data on PMAC elements a review of the available literature was performed. Details of the analyses are contained in Appendix $C$ and those results will only be summarized in the following sections. Tables II and III present equations for he element masses and dissipated powers for both the conventional DC and the AC concepts, respectively.

Conventional DC PMAC Approach. - The conventional PMAC system was described previously $(10,11)$ in single point system designs along with the photovoltaic power system. (17)

Figure 1 shows the conventional PMAC of the thrust module consisting of the beam, discharge, and low voltage supplies. It is assumed that each thruster, including any redundant ones. requires one each of these power supplies.

Both the beam and discharge supplies were assumed to be of the series resonant type. (18) This concept has been highly developed for electric propulsion application and has particular promise for application at high power levels. The parametric evaluation of the beam and discharge supplies utilized data from point designs for thrusters operated at 2,2.2, and $6 \mathrm{~kW}$. (18-20) Tables II and III show the results of the evaluation for values of beam and discharge powers greater than 2.0 and $0.3 \mathrm{~kW}$, respectively. The dissipated powers assume constant beam and power supply efficiencies of 0.92 and 0.88 , respectively. Figure 5 graphically presents the beam supply characteristics between 2 and $1000 \mathrm{~kW}$. 
The low voltage supplies were assumed to be of the square wave output type employing magnetic amplifier control. (10) Each low voltage supply was assumed to have a fixed output power of $50 \mathrm{~W}$ (Appendix B) and a fixed efficiency of 0,625.

The Conventional PMAC interface module contains the beam and discharge reconfiguration units, a distribution inverter, a housekeeping converter, and a thrust system controller. The latter three elements are assumed identical for both the PMAC concepts evaluate $t$.

The distribution inverter supplies about $80 \mathrm{~W}$ to the low voltage supplies at an assumed efficiency of 0.9 . The mass and total output power of the distribution inverter is dictated by the number of active thrusters $\left(N^{\prime}\right)$ chosen. For system calculations one redundant distribution inverter was assumed.

A housekeeping converter(10) was assumed to supply power to drive the logic systems of supplies in the thrust module and the thrust system controller and intermittent power to other thrust module elements. In addition, the converter defined previously $(10)$ was assumed to supply a constant $0.4 \mathrm{~kW}$ to other systems of the spacecraft. This capability will also be assumed. Based on the point design of Ref, 10 the equations for the converter mass and dissipated power were obtained as shown on Tables II and III. The efficiency of the converter was assumed constant at $0.9(10)$ and one redundant converter was also assumed for system mass calculations.

A thrust system controller for a 10 thruster system was previously defined (10) The mass and dissipated power of that controller were $4 \mathrm{~kg}$ and $15 \mathrm{~W}$, respectively. For system calculations it will be assumed that the mass and dissipated power of the controller remain constant at the values given in Ref, 10. This was assumed as the controller consists of very lightweight logic systems which will negligibly impact overall system design.

Beam and discharge supply reconfiguration units were studied(10) for a conventional DC power system. In that study the beam and discharge supply input filters were assumed to be part of the reconfiguration units. In this study the input filters were assumed contained in the thrust module supplies. For the conventional case the reconfiguration units are, therefore, basically just power distribution cables. The cabling mass is assumed proportional to the input power to the beam and discharge supplles and the efficiency for the DC case was taken to be 0.995.

AC PMAC Approach. - For the AC system approach all PMAC elements are assumed identical to those of the DC system except for the beam supplies and the beam and discharge reconfiguration units. 
The reconfiguration unit was assumed to be a transformer which fed $1200 \mathrm{~Hz}$ pc wer to the beam and discharge supplies. A preliminary analysis of the discharge supply indicated that, due to several tradeoffs, its characteristics were nearly identical to those for the DC case. The beam supply was, however, as sumed to consist of a three phase full wave rectifier, a low pass LC filter, and breaker type switch gear. The development of the parametric data for both the beam supply and reconfiguration unit are presented in Appendix $\mathrm{C}$ and the results are shown in Tables II and III

\section{Thermal Control}

The thermal control system rejects dissipated powers from both the thrust and interface module by radiation to space. A thermal control system consisting of single sided radiators and heat pipes was assumed. A detailed analysis of such a system was presented in Ref. 6 in which various parameters, such as heat pipe spacing, were optimized. Again, the thermal control system was designed to accommodate Shuttle landing and IUS loads. The radiators were assumed to receive no direct solar flux but had a view factor of about 0,15 to other spacecraft elements, such as solar arrays, that received an equivalent one Astronomical Unit (AU) solar flux. In addition, the overall thermal control system was sized to maintain critical element baseplate temperatures at about $333 \mathrm{~K}\left(60^{\circ} \mathrm{C}\right)$.

For the selected design of Ref. 6 the specific mass of the thermal control sys-

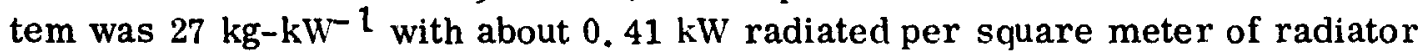
frontal area.

In this study it will be assumed that it is necessary to maintain critical baseplate temperature at $323 \mathrm{~K}\left(50^{\circ} \mathrm{C}\right)$ rather than $333 \mathrm{~K}$, as assumed in Ref. 6. This has the effect of increasing the required radiator frontal area by about 15 percent. The specific thermal control system mass assumed herein will therefore be taken as:

$$
\mathrm{M}_{\mathrm{TH}}=31 \mathrm{P}_{\mathrm{DIS}}
$$

Also it will be assumed that $0.35 \mathrm{~kW}$ is radiated per square meter of radiator frontal area. It is likely that both the mass and area estimates of the thermal control system are conservative because radiation from only one side of the radiator was assumed.

\section{Propellant Tankage}

Either pressurized noncryogenic or cryogenic propellant tank concepts may be required for propellants of interest. Both concepts will be considered separately below. 
Pressurized noncryogenic tanks, - In pressurized spherical tanks it is usual to calculate the tank mass based on the tank wall thickness required to withstand a stress, S, given by:

$$
S=\frac{P_{P} R_{T}}{2 t}+\frac{M_{P} G}{2 \pi R_{T} t}
$$

The first and second terms of the right hand side of Equation (2) account, respec. tively, for tangential stresses induced by the internal tank pressure, $P_{\mathbf{P}}$, and by stresses arising from space vehicle accelerations. The ratio of tank mass $\mathbf{M}_{\mathrm{T}}$, to propellant mass, $M_{p}$ can be obtained directly from Equation (2) for a spherical tank as:

$$
\frac{M_{T}}{M_{P}}=\frac{3}{2} \frac{\rho_{T} X}{\rho_{P} S}\left[P_{P}+G\left(\frac{M_{P}}{2 \pi}\right)^{1 / 3}\left(\frac{4 \rho_{P}}{3}\right)^{2 / 3}\right]
$$

If a small cylindrical section exists in a basically spherical tank, Equation (3) may he used with adequate accuracy if the left hand term in the bracket is doubled to account for axial loads.

Equation (3) may be used to predict tankage mass fractions for many candidate propellants. Tank masses for mercury and xenon will be discussed below.

Many stainless steel mercury propellant tanks have been designed and fabricated. $(4,10,11)$ In mercury tanks the maximum storage pressure is usually about 3. $45 \times 10^{5} \mathrm{~Pa}(50 \mathrm{psi}$ ) and a value of $\mathrm{G}$ of about 9 is typically selected to account for Shuttle landing loads, If a safety factor, $X$, of three is assumed, and an allowable stress, $\mathrm{S}$, of $2.06 \times 10^{8} \mathrm{~Pa}\left(3 \times 10^{4} \mathrm{psi}\right)$, a ratio of spherical tani mass to propellant mass of 0.011 is obtained for a propellant mass of $1000 \mathrm{~kg}$. In practice, most mercury tanks have a cylindrical section which would result in a tankage fraction of 0.0144 . Thls value is in good agreement with the detailed mercury tank design presented in Ref. 10.

Xenon storage has also been evaluated. (21) Reference 21 showed that xenon could be stored at pressures ranging from $4 .{ }^{2} \times 10^{6}$ to $15 \times 10^{6} \mathrm{~Pa}$ (580 to 2175 psi) with temperatures up to $323 \mathrm{~K}\left(50^{\circ} \mathrm{C}\right)$. For a titanium spherical tank, a safety factor of unity, and a load factor of 9 ; the xenon tankage mass traction for a propellant inass of $2.77 \times 10^{3} \mathrm{~kg}$ is calculated from equation 3 as 0.144 . For purposes of calculation a pressure of $1.013 \times 10^{7} \mathrm{~Pa}$ (1470 psi) was assumed along with a xenon density (21) of $1.15 \times 10^{3} \mathrm{~kg}-\mathrm{m}^{-3}$. This tankage fraction is conservative. As pointed 
out in Ref. 21, use of new composite materials could probably reduce the tankage mass fraction to about 0.09 .

Cryogenic tanks. - The tankage mass fraction of a cryogenic argon tank was calculated based on a detailed point design $(22)$ and was presented previously, (12) The tankage mass fraction for the cryogenic argon tank concept presented in Ref. 12 is accurately represented by:

$$
\left(\frac{\mathrm{M}_{\mathrm{T}}}{\mathrm{M}_{\mathrm{P}}}\right)_{\mathrm{CRY}} \approx\left(\mathrm{M}_{\mathrm{P}}\right)^{-1 / 3}
$$

Equation (4) predicts a tankage mass fraction of 0.1 for $1000 \mathrm{~kg}$ of argon propellant. This is more than a factor of five over that previously shown to be required for an equal mass of mercury. It is felt, therefore, that use of Equation (4) will account for the expected space vehicle acceleration loads. To account for propellant density effects the cryogenic mass tankage fraction will be taken as:

$$
\left(\frac{\mathrm{M}_{\mathrm{T}}}{\mathrm{M}_{\mathrm{P}}}\right)_{\mathrm{CRY}} \approx \frac{\rho_{\mathrm{AR}}}{\rho_{\mathrm{P}}}\left(\mathrm{M}_{\mathrm{P}}\right)^{-1 / 3}
$$

\section{Interface Module Structure}

The interface rıodule structure supports the thrust module and all elements of the interface module and serves as the connection to the payload. A detailed evaluation of structure is beyond the scope of this report and the 'etailed analysis of Ref. 10 will be used as a baseline. In Ref. 10 the total mass of the thrust and interface modules, including $1810 \mathrm{~kg}$ of propellant, was $2820 \mathrm{~kg}$. The interface module structural mass, designed to account for IUS and Shuttle landing loads and to support the thrust system, was calculated at $38.4 \mathrm{~kg}$, or approximately 1.4 percent of the thrust system mass. The thrust system of Ref. 10 was relatively compact as the dense mercury propellant required a small tanl: relative to most other potential propellants. In order to provide margin in the estimates of overall system characteristics, it will be assumed that the interface module structural mass is given as:

$$
\mathrm{M}_{\mathrm{IMS}} \approx 0.04\left(\mathrm{M}_{\mathrm{TM}}+\mathrm{M}_{\mathrm{IM}}^{\prime}\right)
$$

This value is about three times the interface module structure mass given in Ref, 10 and should provide a conservative mass estimate. 


\section{Transmission Line Characteristics}

For large thrust systems the characteristics of the transmission lines become significant. The mass of an optimum AC or DC transmission line was derived in Ref. 23 as:

$$
M_{L}=\frac{10^{3} \times F_{V} P L}{V_{L}}\left[\Omega_{L} \rho_{L}\left(\alpha_{P S}+\alpha_{H R}\right)\right]^{1 / 2}
$$

The optimum transmission line was selected to minimize the sum of mass of the power system and the transmission line (including any required heat rejection system).

Table IV shows the factor $F_{V}$ for different types of power distribution. The quantity ${ } \rho_{L}$ is given in Table $V$ for several candidate line materials.

The parametrically expressed mass of the transmission line is plotted in Fig. 6 for copper and aluminum with the sum of $\alpha_{\mathrm{PS}}$ and $\alpha_{\mathrm{HR}}$ as a parameter. For an advanced space power system that is carefully designed for light weight, the sum of $\alpha_{\text {PS }}$ and $\alpha_{\mathrm{HR}}$ is probably in the range of 0.01 to $0.1 \mathrm{~kg} /$ watt for present state of the art. Due to the square root dependence of $M_{L}$ on $\left(\alpha_{\mathrm{HR}}+\alpha_{\mathrm{PS}}\right)$, the optimum transmission line mass varies only slowly with those parameters. The mass indicated on the curve is only for the metal busbars; allowance must be made by the system designers for cable insulation and cable supports.

The power loss in the transmission line, for the optimum current density, $\sqrt{\frac{\rho_{L}}{\Omega_{L}\left(\alpha_{\mathrm{PS}}+\alpha_{H R}\right)}}$ is:

$$
\frac{P_{\text {LOSS }}}{P}=\frac{N_{L} I L}{V_{L}} \sqrt{\frac{\Omega_{L} \rho_{L}}{\alpha_{P S}+\alpha_{H R}}}
$$

where $\mathrm{N}_{\mathrm{L}}$ is the number of transmission lines involved. In order to reject transmission line dissipated power without additional radiator surface it may be necessary to use flat conductor":

\section{THRUST SYSTEM EVALUATION}

A methodology which predicts overall thrust system properties is shown on Fig. 7. To provide insight into its use two system approaches were arbitrarily selected for analysis. The basic input assumptions and derived characteristics for both system approaches are shown on Tahle VI. 
The missions selected for thrist system concept evaluation are roughly equivalent to an orbit transfer from LEO to GEO. Concept A assumed the AC PMAC approach that was previously described. Concept B assumed mercury propellant and a conventional DC power source.

In order to illustrate the methodology, thrust system concept A was selected to provide a detailed explanation. For thrust system A arbitrary values of a final mass of $10^{4} \mathrm{~kg}$, specific impulse of 2500 seconds, a mission velocity increment of 6000 $\mathrm{m}-\mathrm{sec}^{-1}$, and a trip time of 150 days were selected. The thrust may then be calrullated as ?. $26 \mathrm{~N}$ from the following equation(12):

$$
\mathrm{T}_{\mathrm{T}}=\frac{{ }_{\mathrm{M}}}{\Delta \mathrm{T}}\left(\mathrm{e}^{\mathrm{V}_{\mathrm{M}} / \mathrm{I}_{\mathrm{SP}} \mathrm{g}}-\mathrm{i} / \mathrm{I}_{\mathrm{SP}} \mathrm{g} \cdot 1.16 \times 10^{-5}\right.
$$

The propellant is also obtained as $2.77 \times 10^{3} \mathrm{~kg}$ from(12):

$$
M_{P}=M_{F}\left(e^{V_{M} / I_{S P}}-1\right)
$$

This propellant mass will be used later to estimate the propellant tank mass.

Thrust Mcdule

Appendix $\mathrm{B}$ discussed in detail the methods to obtain the values of thrust and thruster powers shown on Table VI-B. The masses and dissipated powers shown on Table VI-B were obtrined directly from the data presented in Tables II and III. and in Appendix $\mathrm{C}$.

From Fig. 4 the individual thruster and gimbal masses are obtained as 21 and $7 \mathrm{~kg}$, respectively.

By dividing the system thrust by individual thruster thrust the number of active thrusters, $\mathrm{N}^{\prime}$, is found as 12.2. This number is rounded up to 13 to provide an integral number of thrusters. For a fixed final mass this rounding up has the effect of slightly shortening the trip time from the assumed 150 days to about 141 days.

With the number of active thrusters obtained, the total power into the thrust module is $\mathrm{N}^{\prime}$ times the sum of the dissipated power of each active power supply and the total power into each thruster.

A redundancy factor of 23 percent was arbitrarily chosen. This results in a total number of thrusters, $N$, of 16. In this analysis each thruster is assumed to have a full complement of PMAC. From the value of $\mathrm{N}$ the mass of all the elements of the thrust module may be calculated as based on discussions and eqli tions presented in this paper. 
Interface Module

The propellant tank mass was calculated from Equation (3) using the assumption shown on Table VI-C. It is possible that substantial reductions in xenon propellant tank mass could be achieved if materials of advanced types were substituted for the titanium material assumed. (21)

The interface module PMAC masses and dissipated powers are calculated directly from the data of Tables II and IIL A redundan. listribution inverter, converter, and thr'dst system controller was assumed to derive overall interface module characteristics.

\section{Transmission Line}

The characteristics of the transmission line are shown on Table VI-D. It is important to note that the mass and dissipated power of the transmission line were a consequence of an optimization process which minimized the mass of the power source and transmission line for a fixed input power to the interface module.

Thrust System

The overall characteristics of the conventiinal and AC systems selected for analysis are shown on Table VI-A. The system characteristics are, of course, strong functions of the assumptions utilized. In the examples used in this paper, quite conservative assumptions were empiyed throughout. As examples of these assumptions present day performance parameters were used, only single sided radiation was assumed, and an interface module mass was as sumed which was a factor of three larger than indicated in a previous study. (10) Table VI-A shows that the dry thrust system specific mass was between 16 and $18 \mathrm{~kg}-\mathrm{kW}^{-1}$. for the two concepts cho: .1 . Improvements in technology would be expected to lower the dry specific mass from that predicted for the point designs evaluated.

\section{CONCLUDING REMARKS}

A methodology was presented which allows prediction of the characteristics of thrust systems employing electron bombardment thrusters. Element characteristics were presented parametrically to allow a mission designer to assess the impact of element technology on overall mission performance and requirements. Two point sysiem designs were presented to illustrate the use of the methodology. 


\section{APPENDIX A - IST OF SYMBOLS}

A active ion acceleration area of thruster, $\mathrm{m}^{2}$

A open area of positive accelerator grid, $\mathrm{m}^{2}$

$F_{V} \quad$ transmission line factor from Table IV

G load on propellant tank in units of $\mathrm{g}$

g gravitational constant, $9.8 \mathrm{~m}-\sec ^{-2}$

I transmission line current, A

$\mathrm{I}_{\mathrm{SP}} \quad$ specific impuise, sec

$J_{B} \quad$ ion beam current, $A$

L transmission line length, $m$

M propellant ion mass, AMU

$\mathrm{M}_{\mathrm{B}} \quad$ beam power supply mass, $\mathrm{kg}$

$\mathrm{M}_{\mathrm{C}} \quad$ housekeeping converter mass, kg

$\mathrm{M}_{\mathrm{CB}}$ beam supply total capacitor mass, $\mathrm{kg}$

${ }^{M_{C E B}}$ beam supply control electronics mass, $\mathrm{kg}$

$M_{D} \quad$ discharge power supply mass, $\mathrm{kg}$

$\mathrm{M}_{\mathrm{DI}} \quad$ distribution inverter mass, $\mathrm{kg}$

$M_{F} \quad$ final spacecraft dry mass, $\mathrm{kg}$

$\mathrm{M}_{\mathrm{IM}} \quad$ interface module mass, $\mathrm{kg}$

$\mathrm{M}_{\mathrm{IM}}^{\prime} \quad$ interface module structural mass less structural mass, $\mathrm{kg}$

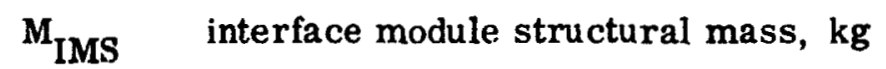

$M_{L} \quad$ transmission line mass, $\mathrm{kg}$

$M_{L C D}$ ieam supply filter and rectifier mass for AC power case, $\mathrm{kg}$ 
$M_{\text {LD }} \quad$ low voltage power supply mass, $\mathrm{kg}$

$\mathrm{M}_{\mathrm{MB}}$ beam supply magnetics and structure mass, $\mathrm{kg}$

$\mathbf{M}_{\mathrm{MCB}}$ beam supply magnetics mass, kg

M OCB beam supply output capacitor mass, $\mathrm{kg}$

$\mathbf{M}_{\mathbf{P}} \quad$ propellant mass, $\mathrm{kg}$

$\mathrm{M}_{\mathrm{RU}} \quad$ reconfiguration unit mass, $\mathrm{kg}$

$\mathbf{M}_{\mathbf{S}} \quad$ switchgear mass, kg

$\mathrm{M}_{\mathrm{T}} \quad$ propellant tank mass, $\mathrm{kg}$

$\mathrm{M}_{\mathrm{TH}} \quad$ thermal control system mass, $\mathrm{kg}$

M $_{\text {TM }} \quad$ thrust module wass, kg

$\mathrm{M}_{\mathrm{TSC}} \quad$ thrust system controller mass, $\mathrm{kg}$

N total number of thrusters

$\mathbf{N}^{\prime} \quad$ number of active thrusters

$\mathrm{N}_{\mathrm{L}} \quad$ number of transmission lines

P total thrust system input power, $\mathrm{kW}$

$\mathbf{P}_{\mathrm{B}} \quad$ individual thruster beam power, $\mathrm{kW}$

$P_{\mathrm{C}} \quad$ housekeeping converter output power, $\mathrm{kW}$

P $_{\text {D } \quad \text { individual thruster discharge power, } \mathrm{kW}}$

$P_{\text {DI }} \quad$ distribution inverter output power, $\mathrm{kW}$

$\mathbf{P}_{\text {DIS }} \quad$ dissipated power, $\mathrm{kW}$

$\mathbf{P}_{\mathrm{F}} \quad$ individual thruster fixed power, $\mathrm{kW}$

$\mathbf{P}_{\text {LB }}$ beam supply dissipated power, kW

$\mathbf{P}_{\text {LC }} \quad$ housekeeping converter dissipated power, $\mathrm{kW}$ 


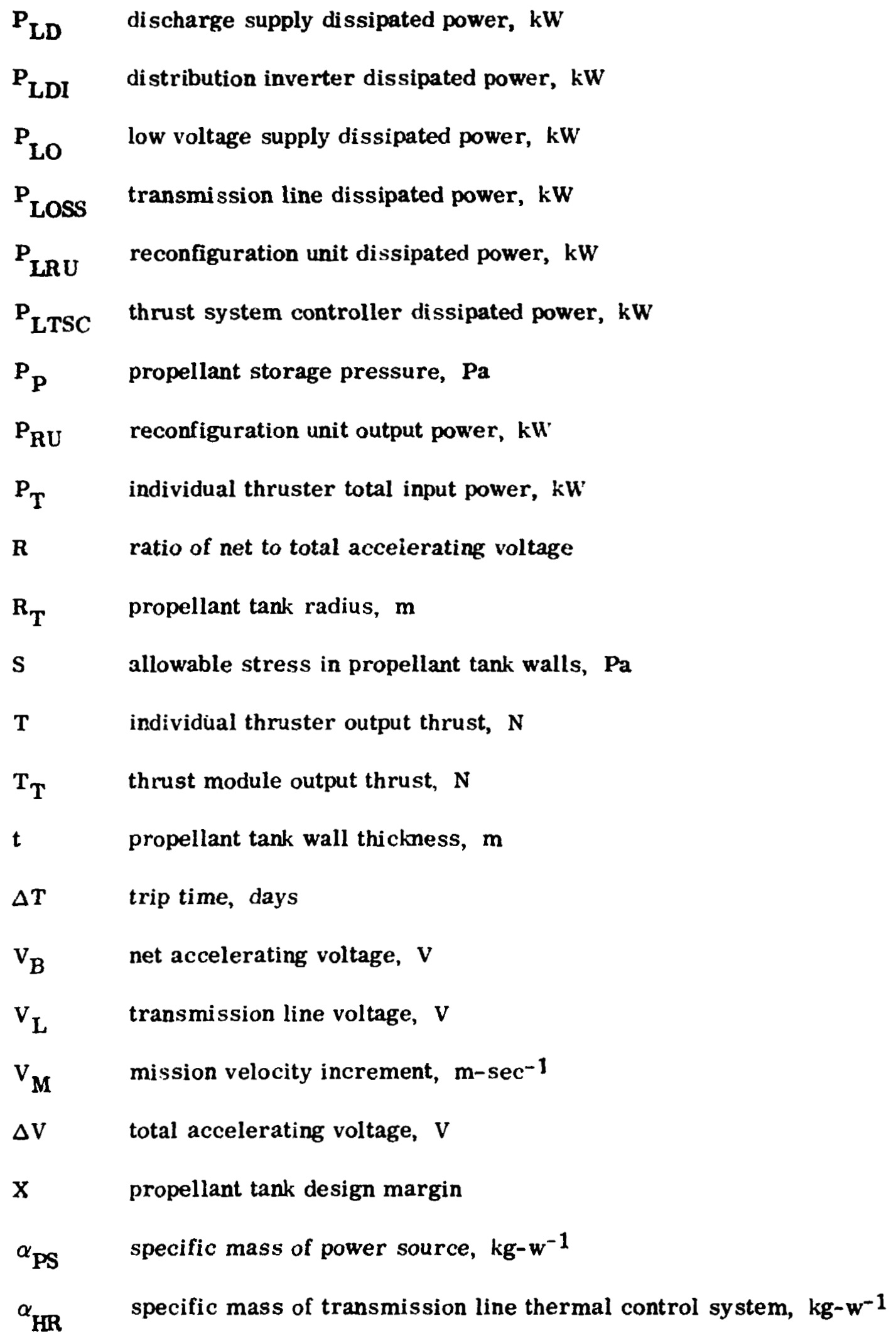


thrust loss factor

$\epsilon \mathrm{V}$ energy required to form an ampere of ion beam, W/A

$\rho_{\mathrm{AR}}$ density of liquid argon, $\mathrm{kg}-\mathrm{m}^{-3}$

$\rho_{L}$ density of transmission line, $\mathrm{kg}-\mathrm{m}^{-3}$

$\rho_{P} \quad$ propellant density, $\mathrm{kg}-\mathrm{m}^{-3}$

$\rho_{\mathrm{T}} \quad$ propellant tank material density, $\mathrm{kg}-\mathrm{m}^{-3}$

$\eta_{U} \quad$ propellant utilization efficiency

$\Omega_{L} \quad$ resistivity of transmission line, ohm-m 


\section{A PPENDIX B}

\section{THRUSTER PER FORMANCE}

Th: operating characteristics of the thruster, such as specific impulse and powel a svel, have a dominu : effect on overall thrust system properties, Detailed $r$. vit $n$; of the operating principles and designs of electron bombardment ion t\}rus rs have been presented elsewhere $(6,12)$ and will not be discussed herein ixcepi as required to describe the limits of thruster operation.

The major constraints on thruster operation(12) are the limit on ion current density (perveance limit) and upper temperature limits. It has been shown(12) that argon 1 iruster operation was limited by temperature constraints only for values ji specif impulse above about 10,000 seconds. For missions of nearest $t \sigma_{\perp} m$ interest, operut in at lower values of specific impulse. where the perveance iimit dominates. is likely to be desirable. Thermal limits will, therefore, be seglected in the following discussion.

Th. perveance limit has been determined expe: imentally for a number of propellants. (24) With state-of-art close spaced ion optics (which maximize the attainable ion current density) this limit was determined to be:

$$
\frac{J_{\mathrm{B}}}{\hat{\therefore}_{\mathrm{O}}} \ddot{<} 5.7 \times 10^{-5} \frac{\Delta \mathrm{v}^{2.25}}{\sqrt{\mathrm{M}}}
$$

Equat on (B-1) $\because$. lws that for a given propellant ion mass the upper limit on ion current density is extremely sensitive to the total accelerating voltage, $\Delta \mathrm{V}$. $\Delta V$ is the sum of the absolute values of voltage applied to the positive and negative accelerator grids. For state-of-art close spaced accelerator grids, total accelerating voltages of greater than 2000 volts have been demonstrated. Although uncertain, 3000 volts is probably near the upper limit that can be obtained with present accelerator grid niaterials and fabrication procedures.

Equation. (B-1) m. . ve rewritten as

$$
\frac{\mathrm{J}_{\mathrm{B}}}{\mathrm{A}} \approx \frac{4.0 \times 10^{-5}}{\sqrt{\mathrm{M}}} \frac{\mathrm{V}_{\mathrm{B}}}{\mathrm{R}} i^{2.25}
$$

To $r^{:}$in E puation (B-2) the positive accelerator grid was assumed to be 70 percent of ' $n$ in agreement wit'. present designs. The total and net accelerating voltages are related through the equation

$$
\mathrm{R} \equiv \frac{\mathrm{V}_{\mathrm{B}}}{\Delta \mathrm{V}}
$$


A previous study(12) of thrusters defined operating limits for thrusters for which two grid ion optics were assumed. For two grid optics the range of acceptable values of $R$ is small, approximately between 0.7 and 0.9 . Subsequently, it has been determined $(13)$ that with three grid ion optics a fixed thruster design will operate over a wide range of the ratio of net to total accelerating voltage, $R$, from about 0.2 to 0.9 . Variation of $R$ at a fixed total accelerating voltage has the effect of varying the ion accelerating voltage and, hence, the specific impulse of the thruster.

From Equation (B-2) the thrust density limit of a bombardment thruster may be computed as:

$$
\frac{T}{A} \approx 5.2 \times 10^{-9} \frac{V_{B}^{2.75} \gamma}{R^{2.25}}
$$

For operating margin in Equation (B-4) the thrust per unit area was reduced by an arbitrary ten percent from the limit defined by Equation (B-2). In Equation (B-4) the thrust loss coefficient, $\gamma$, accounts for multiply charged ions, ion beam divergence, and the small thrust loss due to the difference between the actual net ion energy and that implied by $V_{B}$.

The specific impulse of a bombardment thruster is given by:

$$
\mathrm{I}_{\mathrm{SP}}=1.41 \times 10^{3} \eta_{\mathrm{U}} \gamma / \frac{\sqrt{\mathrm{V}_{\mathrm{B}}}}{\mathrm{M}}
$$

The input power to a bombardment thruster is adequately given as:

$$
P_{T}=10^{-3} \times ! J_{B}\left(V_{B}+\epsilon V\right)+P_{F}
$$

Values of $\epsilon \mathrm{v}$, for propellants of likely application, are presently between about 150 and $250 \mathrm{~W}$ per beam ampere. The lower end of this range is typical of heavy propellants with large ionization cross sections and the upper end of the range is typical of lighter propellants.

The value of $P_{F}$ is negligible when compared with the pou ers required to accelerate and create the ions. For example, $P_{F}$ for the $3 j-\mathrm{cm}, 2.750 \mathrm{~kW}$, mercury thruster is about $50 \mathrm{~W} . P_{F}$ will, therefore, be neglected in calculations of thruster power.

Combination of Equations (B-2) and (B-6) yields an equation for the power density of electron bombardment thrusters: 


$$
\frac{P_{T}}{A} \simeq \frac{3.0 \times 10^{-8}}{\sqrt{M}}\left(\frac{V_{B}}{R}\right)^{2.25}\left(V_{B}+\epsilon V\right)
$$

For operating margin the power per unit area given by Equation (B-7) was reduced by an arbitrary ten percent from the limit inferred by Equations (B-2) and (B-6). In Equation (B-7) the thruster input power, $P_{\mathrm{T}}$, includes both the ion acceleration (beam) and creation powers. For later reference the ion beam power density is given as:

$$
\frac{P_{B}}{A} \approx \frac{3.6 \times 10^{-8}}{\sqrt{M}} \frac{V_{B}^{3.25}}{R^{2.25}}
$$

The ion creation (discharge) power density is defined by:

$$
\frac{\mathbf{P}_{\mathrm{D}}}{\mathrm{A}} \approx 3.6 \times 10^{-8} \frac{\epsilon \mathrm{V}}{\sqrt{\mathrm{M}}}\left(\frac{\mathrm{V}_{\mathrm{B}}}{\mathrm{R}}\right)^{2.25}
$$

To be consistent with the data shown on Figs. 1 and 2 the ion acceleration and creation power densities have been reduced an arbitrary ten percent from limit values.

Inspection of Equation (B-5) indicates that selection of the values of $R$ and $\Delta V$ specifies the specific impulse parameter, $I_{S P} \sqrt{M} / \eta_{U} \gamma$. From Equations (B-3) and (B-4) the values of $R$ and $\Delta V$ also specify the thrust density divided by the thrust loss factor. This ratio will be referred to as the thrust density parameter. If $\epsilon V$ is also specified the value of the thruster input power multiplied by the square root of the ion mass, hereinafter referred to as the power density parameter, is given from Equation (B-7).

The stated conditions allow the thrust and power densities to be plotted as a function of specific impulse parameter for a given assumed value of total accelerating voltage. These plots are given as Figs. 2 and 3 of the main text. To provide operating margin the thrust and power densities shown in Figs. 2 and 3 reflect the arbitrary ten percent reduction from the limits derived from Equations (B-4) and (B-7).

To illustrate the use of the parametric data described above the characteristics of a $50-\mathrm{cm}$ diameter circular xenon thruster will be calculated. For an arbitrary value of specific impulse of 2500 seconds and the performance parameters for xenon shown on Table I the specific impulse parameter is calculated to be $3.17 \times 10^{4}$. If a conservative value of total accelerating voltage of 1750 volts is selected, the thrust 
and power density parameters from Figs. 2 and 3 are $2.31 \mathrm{~N}-\mathrm{m}^{-2}$ and $492 \mathrm{~kW}-\mathrm{m}^{-2}$, respectively. When the thrust density paramet $r$ is multiplied by the thrust loss

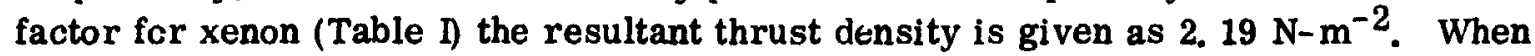
the power density parameter is divided by the square root of the mass of a xenon ion a power density of $42.9 \mathrm{~kW}-\mathrm{m}^{-2}$ is obtained. The resultant thrust and power, after the fixed power loss is added, are $0.43 \mathrm{~N}$ and $8.47 \mathrm{~kW}$, respectively. As stated previously, these values represent a ten percent reduction from the limit implied from Equatio: (B-2).

The jeam and discharge powers are calculated as follows. The value of $V_{B}$ is calculateo as $507 \mathrm{~V}$ from Equation (B-5) as the specific impulse parameter was previously determined. From Equation (B-3) the value of $R$ is obtained as 0.29. Use of the value of $\epsilon \mathrm{V}$ from Table $I$ and Equations (B-8) and (B-9) yields beam and discharge powers of $6.18 \mathrm{~kW}$ and $2.24 \mathrm{~kW}$, respectively. 


\section{A PPENDIX C}

\section{POWER MANAGEMENT AND CONTROL}

Two PMAC concepts are chosen for analysis, a conventional (DC) configuration, (6) and an AC configuration. A parametric description of the masses and dissipated power of the major PMAC elements is developed and results are given in Tables II and III.

\section{Conventional (DC) PMAC System}

As shown in Fig. 1, the thrust module elements consist of conventional beam and discharge supplies and a set of low voltage power supplies which provide the conditioned voltages and currents required by the thruster.

Both the beam and discharge supplies were assumed to be of the series resonant type (18) operating at a conversion frequency of $20 \mathrm{kHz}$. This converter was chosen because of its present state of development for solar electric propulsion and its promising application at higher power levels.

A detailed analysis was performed of series resonant couverters with outputs of 2. $0,2.2$, and $6.0 \mathrm{~kW}(18,19,20,27)$ and of the beam supply used on the SERT II mission $(25,26)$ The converters mass was separated into three major elements-power magnetics, power capacitors, and control electronics.

Power magnetic mass was found to vary approximately to the $3 / 4$ power of the output power and is given by:

$$
\mathrm{M}_{\mathrm{MCB}} \approx 2.5 \mathrm{P}_{\mathrm{B}}^{3 / 4}
$$

For purposes of this analysis the input filter magnetic mass was included in the converter mass assessment. As magnetics mass increases with increasing power the ratio of magnetic mass to structure mass will decrease. A resonable assumption is that the structure to support the power magnetics will vary approximately to the $2 / 3$ power of the magnetic mass. Therefure the magnetic component and its structure are given by

$$
\mathrm{M}_{\mathrm{MB}} \approx 2.5 \mathrm{P}_{\mathrm{B}}^{3 / 4}+1.8 \mathrm{P}_{\mathrm{B}}^{1 / 2}
$$

The second major element is the power capacitor mass. Analysis was performed of the output filter assuming the output ripple must not exceed one percent and the density is approximately 0.1 joule/gm. The mass variation was determined to be: 


$$
\mathrm{M}_{\mathrm{OCB}} \approx 0.025 \mathrm{P}_{\mathrm{B}}
$$

To determine the parametric variation of the total capacitor mass a plot was made of mass versus power for $2.0,2.2$, and $6.0 \mathrm{~kW}$. The equation describing the variation is given by

$$
\mathrm{M}_{\mathrm{CB}} \approx 0.04 \mathrm{P}_{\mathrm{B}}+2.5
$$

The coefficient depends on both the input and output ripple requirements. To achieve one percent ripple it is assumed the power capacitor mass may be approximated by:

$$
\mathrm{M}_{\mathrm{CB}} \approx 0.05 \mathrm{P}_{\mathrm{B}}+2.5 \text { for } \mathrm{P}_{\mathrm{B}}>2 \mathrm{~kW}
$$

The third element of the beam ccnverter mass assessment is the control electronics. This mass was found to remain relative:y independant of power and is given by:

$$
\mathrm{M}_{\mathrm{CEB}} \sim 1.3
$$

The structure to support the nonmagnetic components $\left(\mathbf{M}_{\mathrm{CB}}+\mathbf{M}_{\mathrm{CEB}}\right)$ was assumed to be equal to the component mass.

The mass of the conventional beam supply is expressed by:

$$
\mathbf{M}_{\mathrm{B}} \approx \mathbf{M}_{\mathrm{MB}}+2\left(\mathbf{M}_{\mathrm{CB}}+\mathbf{M}_{\mathrm{CEB}}\right)
$$

or

$$
\mathrm{M}_{\mathrm{B}} \approx 2.5 \mathrm{P}_{\mathrm{B}}^{3 / 4}+1.8 \mathrm{P}_{\mathrm{B}}^{1 / 2}+0.1 \mathrm{P}_{\mathrm{B}}+7.6
$$

The percent efficiency of the series resonant type beam supply and input filter is typically in the low nineties and projected to be 92.9 at $6 \mathrm{~kW}$. (20) It is felt that the efficiency will increase for power outputs as improved switches are developed. For purposes of this paper it is assumed the efficiency is a constant 93 percent throughout the power range. The dissipated powers are approximated by:

$$
\mathbf{P}_{\mathrm{LB}} \sim \frac{7}{93} \mathbf{P}_{\mathrm{B}}
$$

Parametric analysis of the discharge supply mass is identical to that of the conventional beam supply. The mass is given by:

$$
M_{D} \sim 2.5 P_{D}^{3 / 4}+1.8 P_{D}^{1 / 2}+0.1 P_{D}+3
$$


Analysis of the efficiencies of the discharge supplies (18-20) showed them to remain nominally constant at 88 percent. For this analysis it is assumed this efficiency will be nominally constant at 88 percent for discharge powers up to $50 \mathrm{~kW}$ because of the low voltage high current output of this supply. The dissipated power is expressed by:

$$
P_{\text {LD }} \sim \frac{3}{22} P_{D}
$$

The third major element of the conventional PMAC system is the low voltage power supplies. The mass of these supplies together with the command, data, and protection systems was found to be nominally constant and is expressed by:

$$
\mathbf{M}_{\mathbf{L D}} \sim 15
$$

Analysis of these supplies ${ }^{(6)}$ showed the output power to be about 50 watts and dissipative losses to be about 30 watts.

The interface module contains the beam and discharge power reconfiguration units, a distribution inverter fo : the low voltage supplies, a house keeping converter, and a thrust system controller. The latter three are the same for either PMAC concept and only the reconfiguration units differ.

The reconfiguration unit for the conventional PMAC system is assumed to consist only of interconnecting wiring and filtering. It is assumed the mass would be approximated by:

$$
\mathrm{M}_{\mathrm{RU}} \sim 0.15 \mathrm{~N}\left(\mathrm{P}_{\mathrm{B}}+\mathrm{P}_{\mathrm{LB}}+\mathrm{P}_{\mathrm{D}}+\mathrm{P}_{\mathrm{LD}}\right)
$$

Efficiency was assumed to be about 99.5 percent and the dissipated power given by:

$$
\mathrm{P}_{\text {LRU }} \sim 0.005 \mathrm{P}_{\mathrm{RU}}
$$

(where $\left.P_{R U}=\left(P_{B}+P_{L B}+P_{D}+P_{L D}\right) N^{\prime}\right)$

The distribution inverter chosen provides $A C$ power of about 80 watts to each thruster. Size and mass of the unit is dictated by the number of active thrusters $\left(\mathrm{N}^{\prime}\right)$ chosen. The mass is approximated for powers greater than $300 \mathrm{~W}$ by:

$$
\mathrm{M}_{\mathrm{DI}} \sim \mathrm{P}_{\mathrm{Dl}}^{3 / 4}+\mathrm{P}_{\mathrm{DI}}^{1 / 2}+0.1 \mathrm{P}_{\mathrm{DI}}+0.2
$$


Efficiency was assumed to be relatively constant at about .0 percent when the unit is operated near full capacity. The dissipated power is expressed by:

$$
P_{\text {LDI }} \sim \frac{1}{9} P_{D I}
$$

(where $P_{D I}=N^{\prime} \times 0.08 \mathrm{~kW}$ )

The house keeping converter provides 400 watts to support spacecraft loads and approximately 30 watts per active thruster for logic power and telemetry. The mass is approximately by:

$$
\mathrm{M}_{\mathrm{C}} \sim \mathrm{P}_{\mathrm{C}}^{3 / 4}+\mathrm{P}_{\mathrm{C}}^{1 / 2}+0.1 \mathrm{P}_{\mathrm{C}}+0.9
$$

where $P_{C}=0.03 N^{\prime}+0.4$

Efficiency was assumed to be 90 percent when the unit is operated near full capacity. The dissipated power is expressed by

$$
\mathrm{P}_{\mathrm{LC}} \sim \frac{1}{9} \mathrm{P}_{\mathrm{C}}
$$

The thrust system controller provides operational control, data, and safe guarding functions. The mass of this unit is assimed to remain constant at about $4 \mathrm{~kg}$ with losses of about 15 watts.

\section{AC PMAC System}

The AC PMAC system concept assumed a 3 phase distribution transformer which provided multiple outputs for the individual beam and discharge supplies. The emphasis in this concept was to minimize losses and the resulting thermal control mass. Discharge and low voltage power supplies in the thrust module are the same as those used in the conventional PMAC system.

Each beam supply was configured with a 3 phase full wave rectifier, a low pass LC filter consisting of a heat pipe cooled inductor, and switchgear. The output ripple was assumed to be one percent. The parametric mass of the $\mathrm{L}-\mathrm{C}$ filter and rectifiers was ralculated and is given by

$$
\mathrm{M}_{\mathrm{LCD}} \sim 0.12 \mathrm{P}_{\mathrm{B}}
$$

and the switchgear mass is estimated as

$$
\mathrm{M}_{\mathrm{SG}} \sim 0.08 \mathrm{P}_{\mathrm{B}}^{2 / 3}
$$


Including the structure mass which is assumed to vary as the $2 / 3^{\prime} \mathrm{s}$ power of $M_{L C D}+M_{S G}$ the mass of the beam supply is approximated by

$$
\mathrm{M}_{\mathrm{B}} \sim 0.12 \mathrm{P}_{\mathrm{B}}+0.32 \mathrm{P}_{\mathrm{B}}^{2 / 3}+0.18 \mathrm{P}_{\mathrm{B}}^{1 / 2}
$$

Efficiency is assumed to be 98 percent and the dissipated power is expressed by

$$
P_{L B} \sim \frac{1}{49} P_{B}
$$

The beam and discharge power reconfiguration unit of the AC PMAC syste the only interface module element that differs between the two systems. This consists of the 3 phase distribution transformer that supplies input power at 1. $2 \mathrm{kHz}$ to the beam. and discharge supplies. Power magnetics in the conventionial PMAC system were optimized for their specific design points using conventional cooling techniques. Heatpipe cooling was assumed in the conceptual design of the 3 phase transformer in the AC PMAC system. Incorporation of heat pipes into transformers has shown that the total mass is significantly reduced. Additionally the mean winding temperatures are lowered leading to higher reliability and longer life. Calculations show the mass of such a transformer would be about 110 kilograms for an output of 100 kilowatts and a frequency of $1200 \mathrm{~Hz}$. Scaling on this design point, the mass of the transformer and its support structure is approximated by:

$$
\mathrm{M}_{\mathrm{RU}} \approx 3.5 \mathrm{P}_{\mathrm{RU}}^{3 / / 4}+2.3 \mathrm{P}_{\mathrm{RU}}^{1 / 2}
$$

Losses were assumed to be about one percent.

$$
\mathrm{P}_{\text {LRU }} \sim \frac{1}{99} \mathrm{P}_{\mathrm{RU}}
$$




\section{REFER ENCES}

1. Bekey, I., "Big Comsats for Big Jobs at Low User Cost," Astronautics and Aeronautics, " Vol. 17, Feb. 1979, pp. 42-56.

2. Disher, J. H., "Next Steps in Space Transportation and Operations, " Astronautics and Aeronautics, Vol. 16, Ja.2. 1978, pp. 22-si.

3. "Initial Technical, Environmental, and Econcmic Evaluation of Space Power Concepts, Vol. I - Summary, " NASA TM X-74309, 1976.

4. Kerslake, W. R., and Ignaczak, L. R., "Status of SERT II Spacecraft and Ion Thrusters," ALAA Paper 78-662. Apr. 1978.

5. "Scrt C Pri ect Study," NASA TM X-71508, 1974.

6. Hawthorne, E. I. Weisman Y. C., Frisman, M., Renson, G. C. , McGrath, R. J., Martinelli, R. M. Linsenbardt, T. L, and Beattie, J. R., "Extended Performance Solar Electric Propulsion Thrust System Study, Vol. III, Tradeoff Studies of Alternate Thrust System Configurations, "Hughes Research Labs. , Malibu, Calif. and Hughes Space and Communications Group, Los Angeles, Calif., Sep. 1977 (NASA CR-135 281).

7. Masek, T. D., MacPherson, D., Gelon, W., Kami, S., Poeschel, R. L., and Ward, J. W. , "Advanced Electrostatic Ion Thruster for Space Propulsion," Hughes Research Labs, , Malibu, Calif., Apr. 1978 (NASA CR-159406).

8. Duxbury, J. H., "An Integrated Solar Electric Spacecraft for the Encke Slow Flyby Mission, "AIAA Paper 73-1i26, Nov. 1973.

9. Barthelemy, R. R., Koester, R. J.. Stearns, J. W. , and Stofel, E. . "Aerospace Power Systems - A Building Surge, "Astronautics and Aeronautics, Vol. 17, Feb. 1979, pp. 34-72.

10. Poeschel, R. L. and Hawthorne, E. I. , 'Extended Performance Solar Electric Propulsion Thrust System Study, Vol. II. Baselire Tlirust System, "Hughes Research Labs, Malibu, Calif. and Hughes Space and Communications Group, Los Angeles, Calif., Sep. 1977 (NASA CR-135281).

11. Cake, J. E., Sharp, G. R., Oglebay, J. C., Shaker, F. J., and Zavesky, R. J., "Modular Thrust Subsyster Ipproaches to Solar Electric Propulsion Module Design, " AIAA Paper 76-1062, Nov. 1976. 
12 Byers, D. C., and Rawlin, V. K., "Critical Elements of ElectronBombardment Propulsion for Large Space Systems, " Journal of Spacecraft and Rockets, Vol. 14, Nov. 1977, pp. 648-654.

13. Rawlin, V. K. and Hawkins, C. E., "Increased tpabilities of the 30-cm Diameter Hg Ion Thruster, " AIAA Paper 79-0910, May 1979.

14. Meadows, G. A. and Free, B. A., "Effect of a Decel Electrode on Primary and Charge-Exchange Ion Trajectories, " AIA A Paper 75-427, Mar. 1975.

15. Ramsey, W. D., "Inert Gas Ion Source Program," XEOS- 2361, Xerox ElectroOptical Sys. sms, Pasadena, Calif., July 1978 (NASA CR-159423).

16. Isaacson, G. C., "Multipole Gas Thruster Design," Colorado State University, Fort Collins, Colo., June 1977 (NASA CR-135101).

17. Wright, J. J., "Natural Environment Design Criteria for the Solar Electric Propulsion Stage (SEPS), " NASA TM $\approx-64929,1975$.

18. Biess, J. J., Inouye, L. Y.., and Schoenfeld, A. D. "Electric Prototype Power Processor for a $30 \mathrm{Cm}$ Ion Thruster, " TRW-28014-6001-TU-00, TRW Defense and Space Systems Group, Redonda Beach, Calif., Mar. 1977. (NASA CR-135287)

19. Bieos, J. J., Schoenfeld, A. D., and Cohen, E., "Power Processor for a $20 \mathrm{Cm}$ Ion Thruster, "TRW-20384-6002-RU-00, TRW Defense and Space Systems Group, Redondo Beach, Calif., Oct. 19;3. (NASA CR-121160)

20. Biess, J. J., Inouye, L. Y., and Schsenfeld, A. D., "Extended Performance Electric Propulsion Power Processor Design Study Vol. 2 - Technical Suminary," TRW-31526.000-VOL-2, TRW Defense and Space Systems Group, Redondo Beach, Calif., Nov. 1977. (NASA CR-135358)

21. Burkhart, J. A. and Seikel, G. R., "Feasbility Studies of an Auxiliary Propulsion System Using MPD Thrusters, " AIAA Paper 71-695, June 1971.

22. Cacuy, E. C., private communication, McDonnell Douglass Astronautics Co., Huntington Beach, Calif., 1975.

23. Finke, R. C., Myers, I. T., Terdan, F. F., and Stevens, N. J., "Power Management and Control for Space Systems, " Future Orbital Power Systems Technology Requirements, NASA CP-2058, 1978, pp. 195-207. 
24. Sovey, J. S., "A 30-cm Diameter Argon Ion Source, " AIAA Paper 76-1017, Nov. 1976.

25. Hoffman, A. C., Bauer, S. F., Briggs, R. W., Swiderski, E. F., and Weger, R. M. . "Power Conditioning Development for the Sert II Ion Thruster, "Proceedings of the 4th Intersociety Energy Conversion Engineering Conference, American Institute of Chemical Engineers, 1969, pp. 975-986.

26. Yorksie, D. S., and Lagadinos, J. L, "Open Construction Magnetic Components for Sert II Power Conditioner, " Proceedings of the 2nd Workshop on Voltage Breakdown in Electronic Equipment at Low Air Pressures, Jet Propulsion Laboratory, 1969, pp. 77-90. (NASA CR-110627)

27. Sharp, G. R., Gedeon, L, and Ogletay, J. C., Shaker, F. S., and Siegert, C. E., "A Mechanical, Thermal and Electrical Packaging Design for a Prototype Power Management and Control System for the $30 \mathrm{CM}$ Mercury Ion Thruster, "AIAA Paper 78-685, Apr. 1978. 


\section{TABLE I. - THRUSTER PER FORMANCE PARAMETERS WITH VARIOUS PROPELLANTS \\ Propellant Propellant Propellant Thrust Power per moss, utilization loss beam ampere, M. efficiency, factor, $\in \mathrm{V}$, $\begin{array}{llll}A M U & \eta_{U} & \gamma & \text { W/A }\end{array}$

$\begin{array}{lcccc}\text { Mercury } & 200.61 & 0.95 & 0.95 & 150 \\ \text { Xenon } & 131.3 & . .95 & \mathbf{2} .95 & 183 \\ \text { Krypton } & 83.8 & .9 & \mathbf{2} .95 & 220 \\ \text { Argon } & 39.9 & .8 & \mathbf{a} .95 & 250\end{array}$ \\ a Beam divergence loss contribution to $\gamma$ taken from data with mercury propellant.}

BRECEDUG PAGE BLABHi NO, $\because: \cdots$ 


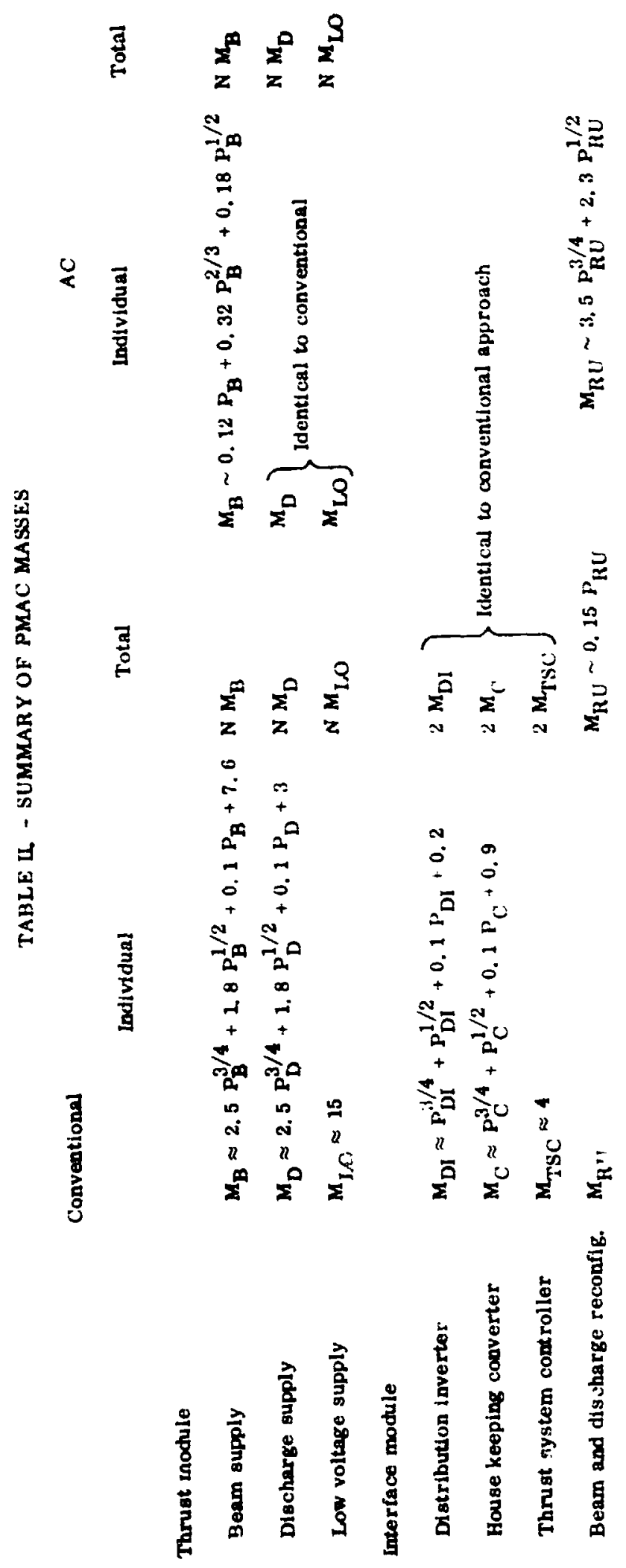




\section{TABLE ILL - SUMMARY OF PMAC DISSTPATED POWERS}

\section{Conventionel}

Individual Total Individual Total

Thrust mor dite

3erm supply

Dis : narge supply

Low voltage supply

Interface module

Distribution inverter

House keeping converter

Thrust system controller

Beam and discharge reconfig.

$$
\left.\begin{array}{ll}
P_{L B} \sim \frac{7}{93} P_{B} & N^{*} P_{B} \\
P_{L D} \sim \frac{3}{22} P_{D} & N^{\prime} P_{D} \\
P_{L O} \sim 0.03 & N^{\prime}(0.0 .)
\end{array}\right\} \text { Identical to conventionai spproach }
$$

$$
\begin{aligned}
& P_{\text {LDI }} \sim \frac{1}{9} P_{D I} \backslash \text { Identical to conventional } \\
& \left.P_{L C} \sim \frac{1}{9} P_{C}\right\} \text { approach } \\
& P_{\text {LTSC }} \sim 0.015 \\
& \mathbf{P}_{\text {LRU }} \sim \frac{\mathbf{N}^{\prime}}{199} \mathbf{P}_{\mathbf{R U}} \quad \mathbf{P}_{\text {LRU }} \sim \frac{1}{99} \mathbf{P}_{\mathbf{R U}}
\end{aligned}
$$




\section{TABLE IV. - VOLTAGE DISTRIBUTION FACTOR}

\section{Type of distribution and method of specifying voltage}

dc, 2 wire

dc, 2 wire, $\pm V$, balanced

dc, 3 wire, $\pm V$, balanced

Single-phase ac, 2 wire, rms

Single-phase ac, 2 wire, $\pm V$, rms, balanced

Single-phase ac, 3 wire, $\pm V$, rms, balanced

Single-phase ac, 2 wire, pk-pk

Single-phase ac, 3 wire, $\pm V$, pk-pk, balanced

Three-phase ac, 3 wire, $V_{L T N}$,rms, balanced

Three-phase ac, 4 wire, $V_{L T N}$ rms, balanced

Three-phase ac, 3 wire, $\mathrm{V}_{\text {LTN }}$ pk-pk, balanced

Three-phase ac, 4 wire, $\mathrm{V}_{\text {LTN }}$ pk-pk, balanced

Three-phase ac, 3 wire, $V_{\text {LTL }}$ rms, balanced

Three-phase ac, 4 wire, V LTL, rms, balanced

Three-phase ac, 3 wire, $V_{\text {LTL }}$, pk-pk, balanced

Three-phase ac, 4 wire, $V_{L T L}$, pk-pk, balanced
Voltage distribution factor, $\mathrm{F}_{\mathrm{V}}$

2. 00

1.00

1. $225(\sqrt{3 / 2})$

2.000

1.000

1. $225(\sqrt{3 / 2})$

$2.828(2 \sqrt{2})$

$1.732(\sqrt{3})$

1.000

1. $155(2 / \sqrt{3})$

1. $414(\sqrt{2})$

1. $633(4 / \leadsto \overline{6})$

1. $732(\sqrt{3})$

2.000

2. $449(\sqrt{6})$

$2.828(2 / 2)$ 
TABLE V. - TRANSMISSION LINE MATERIALS

Materials Density, Resistivity, $\Omega_{\mathrm{I}} \rho_{\mathrm{L}}$,

$\rho_{\mathrm{L}, 3} \quad \Omega_{\mathrm{L}} \quad \mathrm{kg} \mathrm{ohm} / \mathrm{m}^{2}$

$\begin{array}{lrrr}\text { Copper } & 6960 & 1.72 \times 10^{-8} & 1.55 \times 10^{-4} \\ \text { Silver } & 10500 & 1.59 \times 10^{-8} & 1.67 \times 10^{-4} \\ \text { Gold } & 19320 & 2.44 \times 10^{-8} & 4.71 \times 10^{-4} \\ \text { Aluminum } & 2700 & 2.82 \times 10^{-8} & 0.76 \times 10^{-4} \\ \text { Beryllium } & 1850 & 4.0 \times 10^{-8} & 0.74 \times 10^{-4} \\ \text { Sodium } & 970 & 4.3 \times 10^{-8} & 0.42 \times 10^{-4}\end{array}$


TABLE VI-A. - THRUST SYSTEM CONCEPTS

Overall characteristics

Concept

Mission parameters

Velocity increment, $\mathrm{m}-\mathrm{sec}^{-1} \quad 6000 \quad 6000$

Trip time, days

Final mass, kg

Specific impulse, sec

Thrust module

Mass, kg

Input power, $\mathrm{kW}$

Propellant type

Interface module

Dry mass, $\mathrm{kg}$

Total mass, kg

Input power, $\mathrm{kW}$

Transmission line

Mass, kg

Input power, $\mathrm{kW}$

Overall thrust system

Dry mass, kg

Total mass, kg

Input power, $\mathrm{kW}$

Radiator area, $\mathrm{m}^{2}$

Specific impulse, sec

Thrust, N
A $\quad$ B

$150 \quad 150$

$10^{4} \quad 10^{4}$

$2500 \quad 2000$

B

$1233 \quad 1278$

116.199 .7

Xenon Mercury

$791.6 \quad 286.3$

$3562 \quad 3866$

$119.3 \quad 96.9$

$117 \quad 113.7$

$123.2 \quad 102.6$

$2142 \quad 1678$

$4912 \quad 5258$

123. $2 \quad 102.6$

$21 \quad 25$

$2500 \quad 2000$

$5.59 \quad 5.78$ 
TABLE VI-B. - THR UST SYSTEM CONCEPTS

Thrust module

Input assumptions

Derived characteristics
Concept

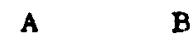

Xenon Mercury

See Table I

Performance parameters

Specific impulse parameter (sec-amui/2)

Net accelerating voltage, $V$

3. $17 \times 10^{4}$ 3. $14 \times 10^{4}$

$507 \quad 496$

$1750 \quad 2000$

2. $31 \quad 3.1$

Thrust density parameter $\left(\mathrm{N}-\mathrm{m}^{-2}\right)$

Power density parameter $\left(\mathrm{kW}-\mathrm{m}^{-2}-\mathrm{amu}^{1 / 2}\right.$

Value of $\mathbf{R}$

492622

0.290 .248

$50 \quad 50$

$0.05 \quad 0.05$

$0.43 \quad 0.578$

$6.18 \quad 6.62$

2. $24 \quad 2.00$

$8.47 \quad 8.67$

2121

$7 \begin{array}{rr}71 & 7 \\ 13 & 10\end{array}$

$141 \quad 139$

PMAC Assumptions

Beam power per thruster, kW

Total thruster power, $\mathrm{kW}$

Thruster mass, $\mathrm{kg}$

Gimbal mase, $\mathrm{kg}$

Active thrusters, $N^{\prime}$

Modified trip time, days

Individual supply mass, kg

Beam

Discharge

Low voltage

Individual supply dissipated power, $\mathrm{kW}$

Beam

Discharge

Low voltage

Total dissipated power, $\mathrm{kW}$

Thermal system assumptions

Thrust module thermal system

Mas8, kg

Area, $\mathrm{m}^{2}$

Thruster redundancy

Structural assumptions

17.122 .8
Number of thru sters, N

Total thruster/gimbal mass, kg

Thrueter module structure mass, kg

Total power supply msss, kg

Propellant distribution mass, kg

Thrust module thrust, N

Thrust module mass, kg

Thrust module input power, $\mathrm{kW}$
See Appendix $C$

$\begin{array}{rr}2.27 & 23,2 \\ 10.5 & 10 \\ 15 & 15\end{array}$

$0.126 \quad 0.5$

$0.305 \quad 0.27$

$0.03 \quad 0.03$

6.08 .0

$186 \quad 248$

0.230 .2

$16 \quad 12$

$448 \quad 336$

$139 \quad 104$

$444 \quad 578$

$16 \quad 12$

$5.59 \quad 5.78$

$1233 \quad 1278$

116.194 .7 
TAYLE VI-C, - THRLST SYSTEM CONCEPTS

Interface module

Input assumptions
Derived characteristics

$\lambda$

Spherical

copellant storage assumptions

Shape

Storage pressure. $\mathrm{Pa}$

propellant density: $\mathrm{kg}-\mathrm{m}^{-3}$

Allowable stress. $\mathrm{Pa}$

Tank material density. $\mathrm{kg}-\mathrm{m}^{3}$

Load factor. \&

Design safety factor. $\mathrm{X}$

Propellant mass, $\mathrm{kg}$

PMIA Assumptions

Thermal asstimptions

Structural assumption
Propellant tank mass. kg

Total masses, lig
Distribution inverters
Converters
Thrust sistem controller
Reconfiguration unit
Dissipated pollers, kll
Distribution inverter
Con erter
Thrust sistem controller
Reconfiguration unit

Interface module thermal si stem Mass, kg

Area, $\mathrm{m}^{2}$

Interface module structure mass, ig Interface module mass, $\mathrm{kg}$ Interface module input power, lill
Concept

F

$\begin{array}{rr} & \text { crlindrical section } \\ 1.01 \times 10^{7} & 3.45 \times 10^{5} \\ 1.15 \times 10^{3} & 1.36 \times 10^{4} \\ 4.12 \times 10^{8} & 2.06 \times 10^{8} \\ 4.5 \times 10^{3} & 7.9 \times 10^{3} \\ 9 & 9 \\ 1 & 3 \\ \therefore 77 \times 10^{3} & 3.58 \times 10^{3} \\ 399 & 34 \\ \text { Sec Appendix C }\end{array}$

t. $7+$

5. 4 5. 1

$8.0 \quad 8.0$

$147.6 \quad 16.9$

$0.12 \quad 0.09$

$0.09 \quad 0.08$

$0.015 \quad 0.015$

1. 160.471

42.9

3.95

20.8

1.9

184

3562

119.8
198

3868

96.9 
TABLE VI-D. - THRUST SYSTEM CONCEPTS

Transmission line characteristics

Input assumptions

Derived characteristics

Concept

A

B

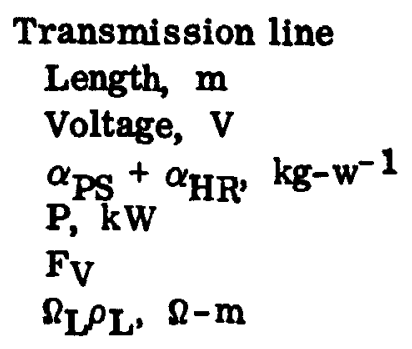

Transmission line mass, $\mathrm{kg}$

Transmission line dissipated power, $\mathrm{kW}$

Transmission line input power, $\mathrm{kW}$

$\begin{array}{rr}450 & 100 \\ 1200(A C) & 300(D C) \\ 0.03 & 0.02 \\ 119.3 & 96.9 \\ 1.732 & 2.0 \\ 7.6 \times 10^{-5} & 1.55 \times 10^{-4} \\ 117 & 113.7 \\ 3.9 & 5.7 \\ 123.2 & 102.6\end{array}$




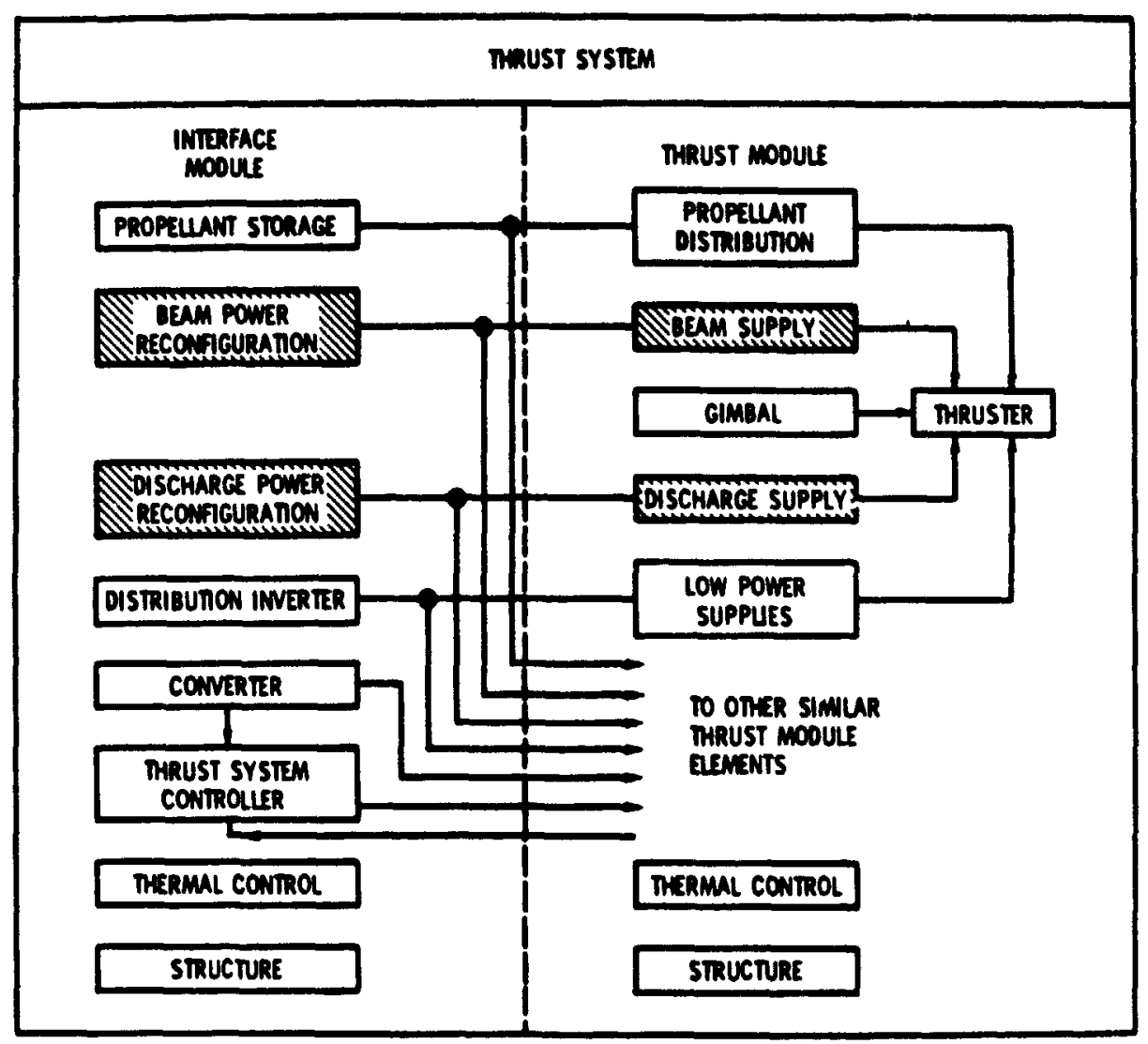

Flgure 1. - Thrust systom appreach. 


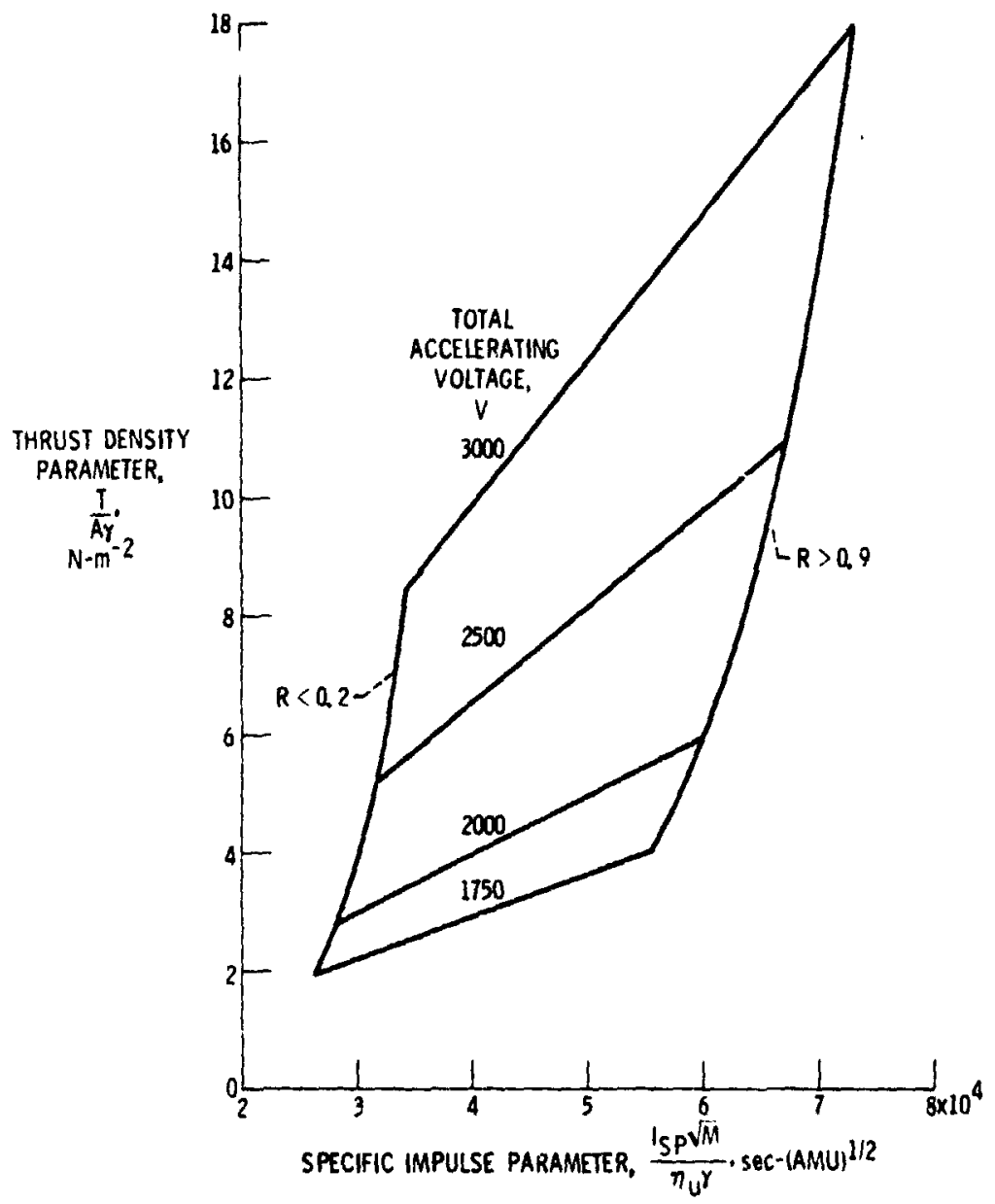

Figure 2. - Thrust density parameter versus specific impulse parameter. Thrust densily reduced 10 percent from limit value. 


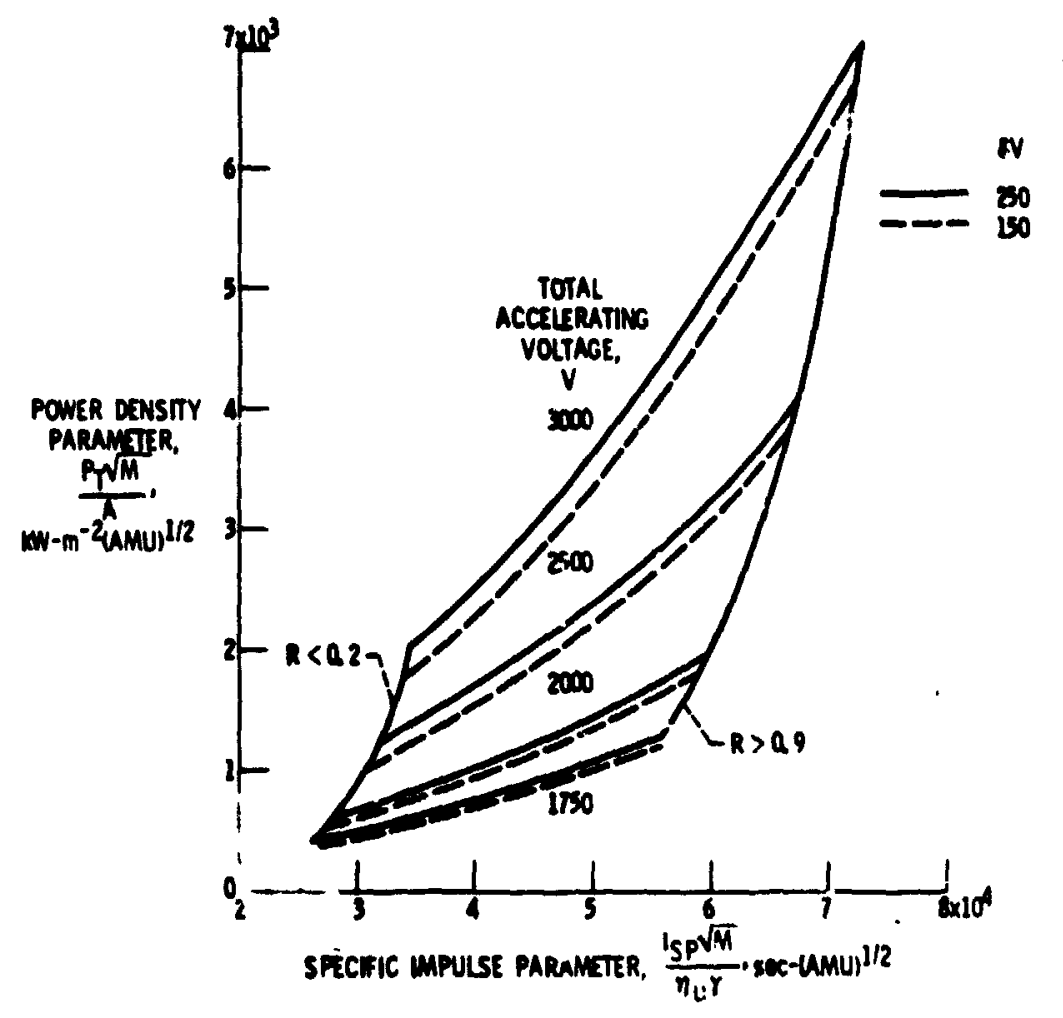

Figure 3. - Aum consity pramater versus specific impulse prom-

Clar. IPeware consity reduced 10 percent from limit value.

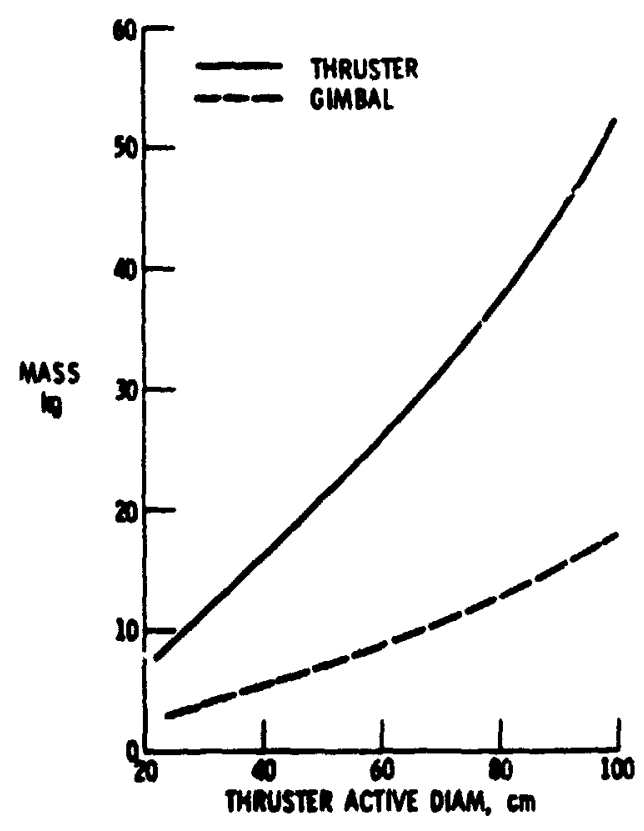

Figure 4. - Theuster end oimbel mass es o function of thruster ective diametor. 

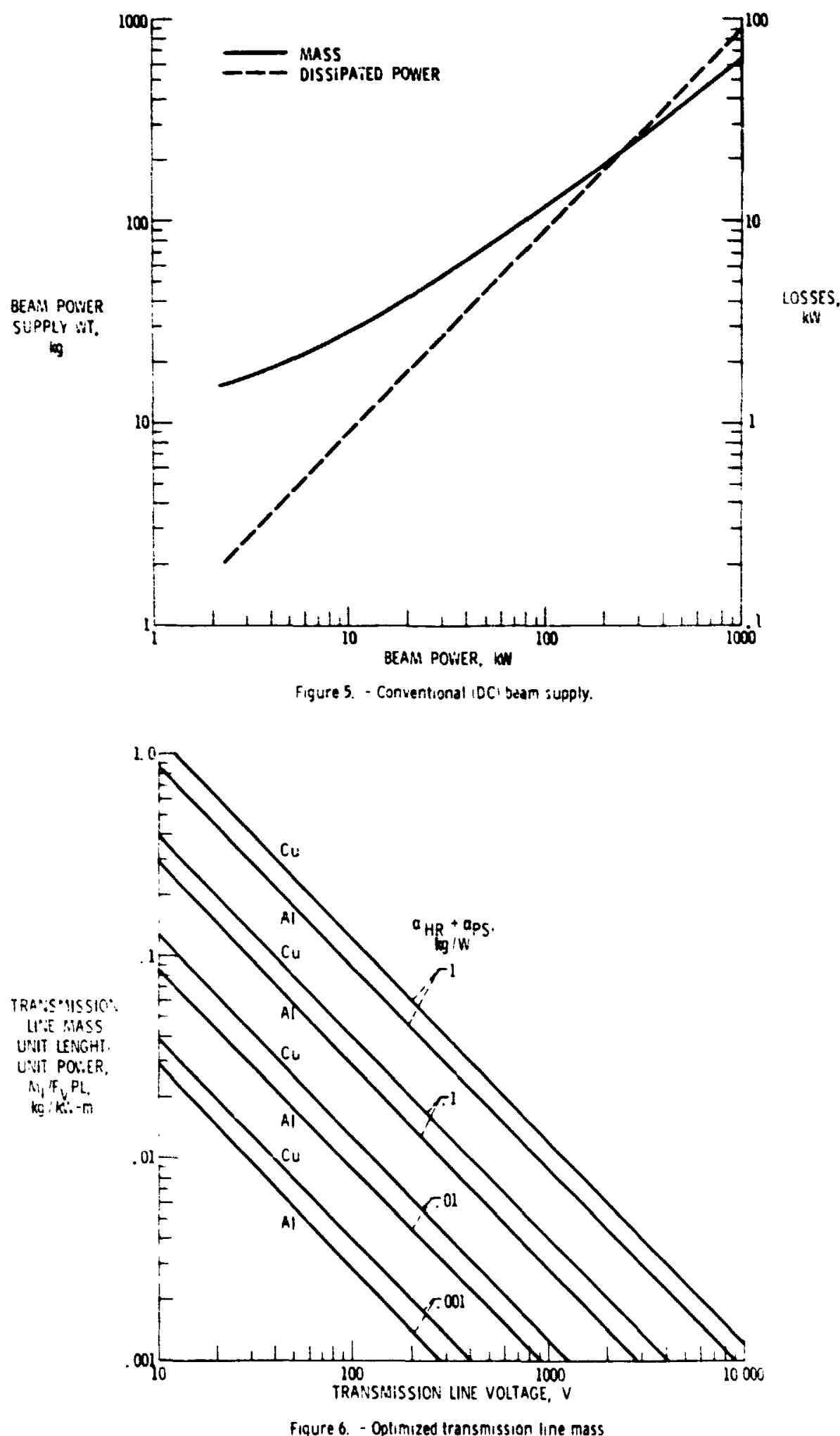
OUTPUTS

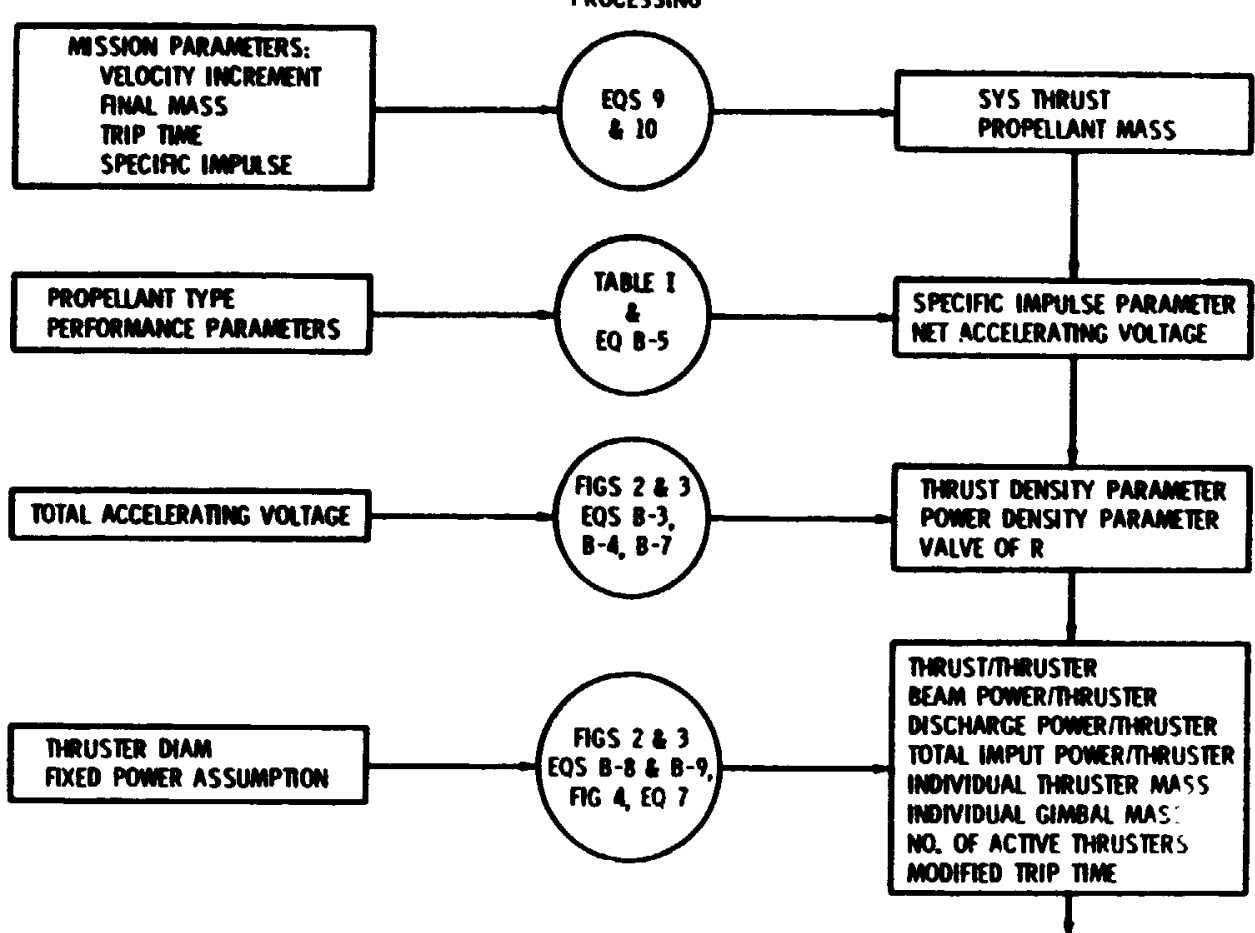

(a) THRUST MODULE DEFINIION METHODOLOGY.

Figure 7.

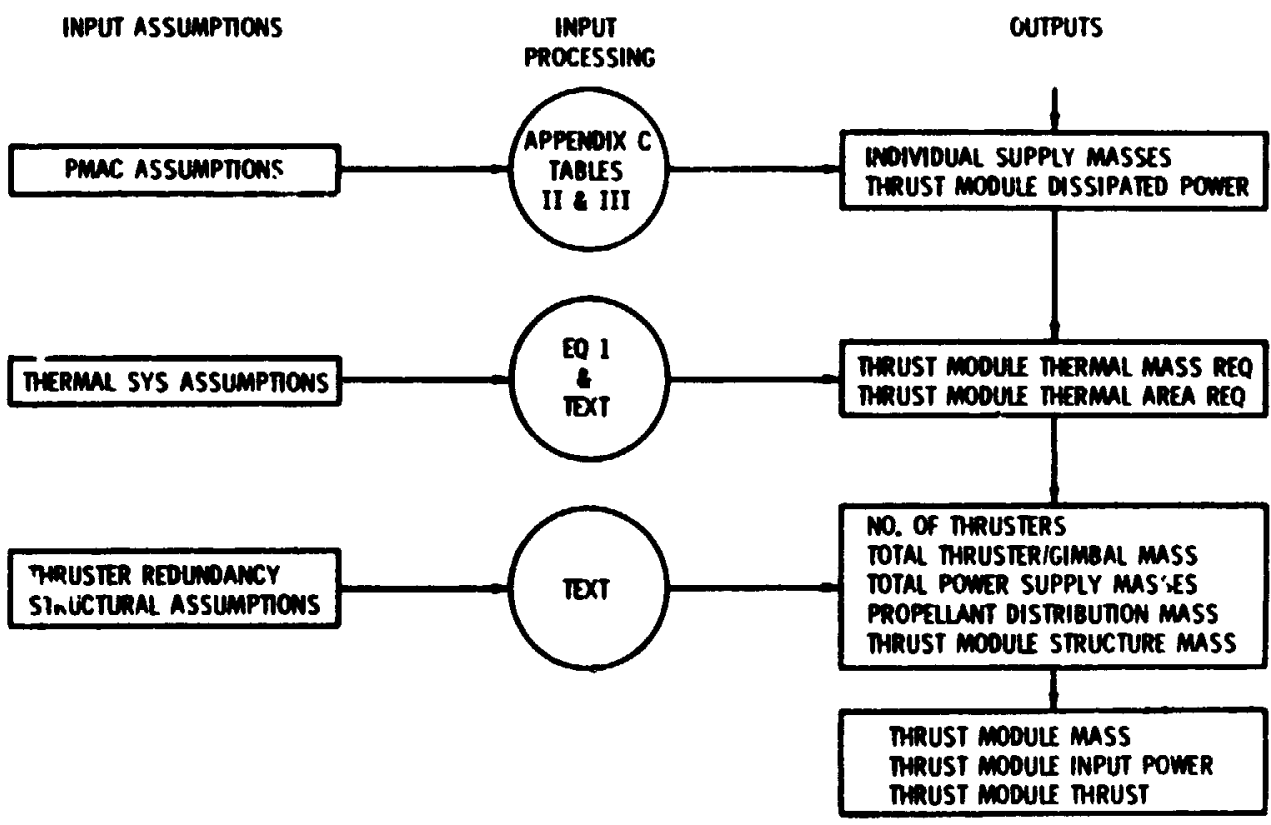

(a) (CONAInUAd) THRUST MODULE DEFINTION METHODOCOGY.

Figure 7. - Continued. 


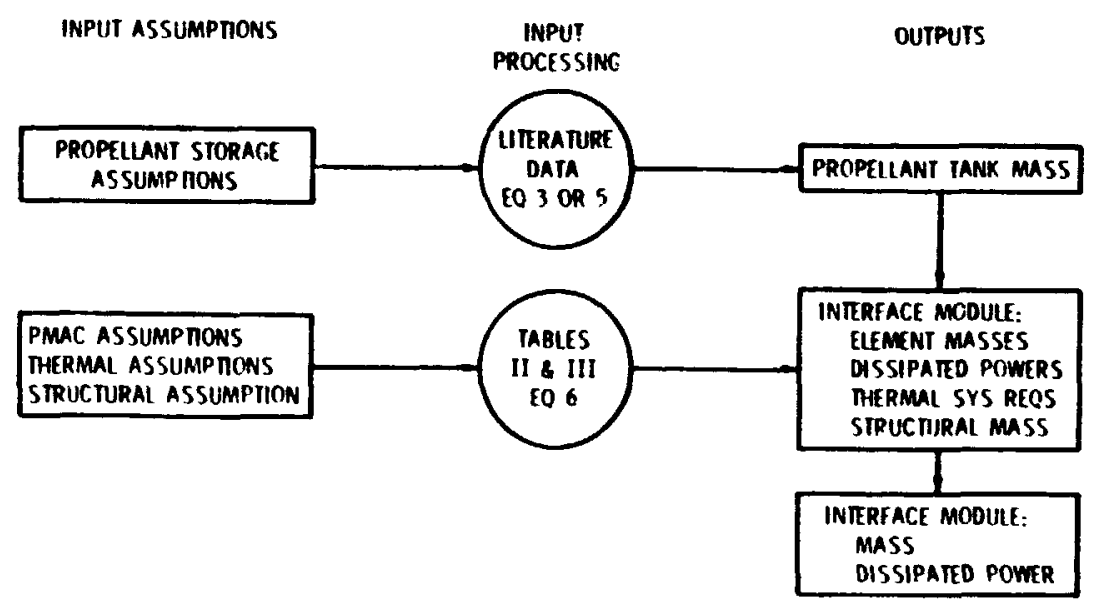

(B) INIERFACE MODUIF DEFINIIION METHOOOOIOCY

tiquel. Continued.

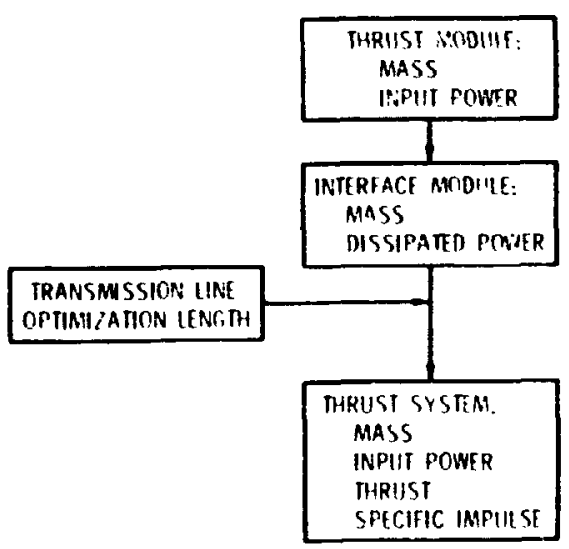

IC THRIST SYSTEM DLHINITION METHODOIOTY

fapure 7. - roncluiter 